\title{
MOVIMIENTO TERRITORIAL INDÍGENA Y GOBIERNOS LOCALES. ETNOGRAFÍA DE CASO EN UNA COMUNA DE LA ARAUCANÍA, CHILE
}

\author{
Indigenous Territorial Movement and Local Governments. Ethnography of Case \\ in a Commune of the Araucanía Region, Chile
}

\section{NATALIA CANIGUAN*}

Fecha de recepción: 09 de octubre de 2018 - Fecha de aprobación: 14 de enero de 2019

\section{Resumen}

En este artículo se analiza el proceso de constitución y desarrollo de un movimiento indígena y territorial vivido en un territorio mapuche lafkenche de la Araucanía durante los años 2000 a 2012. Dicho proceso es reconstruido por medio de un trabajo etnográfico, instancia por medio de la cual fue posible conocer a sus actores y dirigentes, indagar en el contexto y en las diversas variables que fueron dando paso al surgimiento de este movimiento y que configuraron su devenir, y en el que los programas de intervención estatal y la configuración del gobierno local encabezado por personas mapuche se volverán actores de preponderancia.

Palabras clave: movimiento indígena; territorio; gobiernos locales.

\begin{abstract}
In this article, the process of constitution and development of the indigenous and territorial movement lived in the Mapuche Lafkenche territory of the Araucanía region during the years 2000 to 2012 is analyzed. This process is reconstructed through an ethnography, instance through which it was possible to meet its actors and leaders, investigate in context and the diverse variables that were giving way to the emergence of this territorial movement and that shaped its future, where the state intervention programs and the configuration of the local government headed by Mapuche people, who will become preponderant actors in the process.
\end{abstract}

Keywords: territories; indigenous movement; local government.

\footnotetext{
* Mtra. en Desarrollo humano, local y regional. Directora del Instituto de Estudios Indígenas e Interculturales, Universidad de La Frontera, Temuco, Chile. Investigadora del Centro de Estudios Interculturales e Indígenas (CIIR), Santiago, Chile. El artículo se enmarca en el Proyecto Conicyt/Fondap/15110006. Correo-e: natalia.caniguan@ufrontera.cl
} 


\section{Introducción}

La historia sobre el movimiento mapuche de las últimas décadas ha sido diversamente documentada y analizada, siempre a la luz de los contextos en los que se ha desenvuelto y en relación con las dinámicas sociopolíticas del momento en el que se desarrolla. A lo largo de la historia nacional se vislumbra la existencia de movimientos y organizaciones mapuche forjados en una relación de alianza y disputa con el Estado chileno, del que se espera autonomía y a la vez integración. El carácter de estos movimientos tendrá distintos alcances y contenidos, así como diferentes formas de actuar, desarrollarse y cambiar.

Los territorios indígenas, desde la óptica estatal y en el transcurso del tiempo, fueron relegados como espacios pasivos en los que el Estado debía proveer y subsanar carencias vinculadas a la vulnerabilidad socioeconómica, de acuerdo con una visión paternalista y asistencialista en consonancia con la política desarrollista del momento. No obstante, una serie de procesos y cambios en los contextos locales y globales han generado un escenario distinto. Los pueblos indígenas se han convertido en actores claves en el devenir de sus territorios al fijar nuevas demandas y reivindicaciones y enarbolar discursos identitarios y organizacionales, lo que ha generado un cambio de actitud en la relación que el Estado establece con ellos.

Estos movimientos se conciben como parte de un proceso global que actúa desde lo local y con atención en y desde la reivindicación de aquellos elementos que son constituyentes del grupo y que los distinguen de la sociedad mayor en la que se engloban y de la que son parte. Los movimientos indígenas buscan potenciar la etnicidad como elemento diferenciador y sustento de sus demandas y necesidad de reconocimiento (Barth, 1976). La alusión a la territorialidad se volverá un elemento fundante de estos movimientos, en cuanto base de las demandas y característica aglutinadora para diversos grupos, es decir, un elemento identitario y de raigambre histórica sobre la que se proyecta el futuro de los pueblos.

Los municipios o los gobiernos locales se vuelven un actor clave en estos territorios, pues son la representación del Estado en lo local $y$, con ello, la principal fuente de recursos del lugar tanto económicos como políticos. Estos poderes resultan, además, una figura ambigua, pues a la vez que se lucha contra ellos, se requiere de ellos. En este contexto, la existencia de alianzas o no con el municipio se convierte un elemento clave en el desarrollo y el campo de acción de los movimientos locales y en un aspecto esencial en las estrategias planteadas por ambos actores. Las relaciones que se establezcan entre alcaldes y movimientos se volverán, así, fundamentales en el curso que tomarán las reivindicaciones y la orgánica local, pudiéndose observar momentos de trabajo conjunto o de conflicto entre ambas partes. La tríada movimiento social, gobernanza y desarrollo territorial (Ospina, 2006) se convierte en la voz y la base sobre las que constituirse.

La participación en alianzas con el municipio o dentro de la plataforma electoral será otro espacio de intervención y formación. La transformación de los liderazgos dirigenciales en candidaturas políticas será un factor de tensiones, alianzas y, finalmente, el resultado de la validación de la plataforma electoral como una vía de movilización indígena (Espinoza, 2017).

Conocer las dinámicas vividas al alero del proceso de desarrollo de un movimiento 
indígena en territorio mapuche lafkenche será el objetivo de este artículo. Estas dinámicas se muestran cruzadas por las relaciones políticas establecidas por los dirigentes de este movimiento con los alcaldes mapuche que encabezan el gobierno local. Todo esto se da, además, bajo un contexto de políticas públicas focalizadas en el pueblo mapuche y en este territorio, las que se volverán un aliciente más para la conformación del movimiento territorial que aquí se revisará.

Este trabajo se sustenta en una investigación etnográfica de larga data, que abarcó la residencia en el territorio desde el año 2005 hasta 2012. Ser parte del territorio en el que se desenvuelve este estudio permeó la mirada del investigador. Su rol, bajo este enfoque, será un constituyente más dentro de la información recabada y el análisis desarrollado. La vivencia y la reflexividad propia del trabajo de campo (Guber, 2001) serán parte fundante de este escrito.

\section{Hacia la constitución del movimiento territo- rial indígena. Las intervenciones que forjan el movimiento}

El territorio en el que se emplazó esta investigación es un espacio eminentemente mapuche ubicado en el sector costero de la región de La Araucanía, en la zona sur de Chile, que aglutina a un centenar de comunidades indígenas donde pervive con fuerza su cultura. La comuna de Saavedra posee 12.450 habitantes, de los cuales $78,1 \%$ reside en sectores rurales y $81 \%$ declara su adscripción a un pueblo indígena, mayoritariamente mapuche (99\%) (INE, 2017). En lo que refiere a la situación socioeconómica, según la encuesta de Caracterización Socioe- conómica Nacional (CASEN, 2013), 47,14\% de su población se encuentra bajo la línea de la pobreza, lo que supera con creces el promedio regional de $27 \%$ y aún más el nacional de $14,40 \%$. Esto la sitúa, por tanto, dentro de las comunas con mayores índices de vulnerabilidad socioeconómica del país.

Como todo territorio indígena, este no ha estado exento de los procesos de emergencia (Bengoa , 2000) que han vivido los pueblos originarios de América Latina, y tampoco ha quedado ajeno a las intervenciones estatales vinculadas a las políticas multiculturales y/o de reconocimiento de la diversidad.

La década de 1990 en Chile, junto con el retorno a la democracia, fue también un momento en que lo indígena se tomó parte de la agenda política, lo cual quedó expresado en la aprobación de la Ley 19.253, más conocida como Ley Indígena. En ella quedaron estipuladas nuevas formas organizativas, tales como las figuras de comunidades y asociaciones indígenas, y la creación de las áreas de desarrollo indígena (ADI de ahora en adelante), espacios que, veremos más adelante, serán uno de los alicientes en la conformación del movimiento territorial aquí expuesto. Junto a esto, en los procesos participativos democráticos comenzará a surgir y validarse la figura del "alcalde mapuche" (Espinoza, 2017; Caniguan, 2015). De manera paralela, se consolidarán movimientos indígenas que por la vía institucional o fuera de ella (Pairican, 2014) fijarán sus demandas y la agenda sobre la cual el Estado deberá comenzar a hacerse cargo del "tema indígena".

Como acabamos de mencionar, la creación de las ADI será una nueva manera de entender los territorios indígenas, hasta entonces 
supeditados, o más bien invisibilizados, bajo la regencia de las comunas o regiones en los que administrativamente se les insertó. El objetivo de esta nueva delimitación territorial (1997) será focalizar en territorios con alta densidad poblacional indígena la inversión y los recursos estatales con el propósito de disminuir las brechas y las cifras de vulnerabilidad socioeconómica. Se desarrollará de esta manera una visión subsidiaria y de superación de la pobreza como política estatal hacia los pueblos indígenas (Ospina, 2006). La cooperación internacional también resultará clave en estos procesos iniciales organizativos y formativos.

Los límites y los márgenes que constituyeron el territorio aquí estudiado fueron definidos desde el Estado tomando en consideración la existencia de una homogeneidad cultural, las cifras de pobreza, la existencia de troncos familiares, las consideraciones ecológicas y la densidad poblacional (Art. 26). Si bien se consideraron elementos culturales en su determinación, los límites territoriales fueron trazados arbitrariamente por la institucionalidad y superpuestos, por ejemplo, a límites comunales, pero dejando fuera a la vez espacios con vinculaciones sociales o culturales. Esta delimitación fue pensada sobre el espacio físico, sin abrirse a plasmar la existencia de una contraparte territorial con la cual dialogar y sancionar su finalidad.

Como antecedente de lo que fue el proceso organizativo en este espacio, se debe mencionar también la irrupción del ya conocido programa Multifase de Desarrollo Integral de Comunidades Indígenas, conocido popularmente como Programa Orígenes, el cual surgió a partir de un préstamo solicitado por el Estado de Chile al Banco Interamericano de Desarrollo (BID) y comenzó a operar a partir de 2001 en lo que fue su primera fase. El énfasis de esta intervención estuvo puesto principalmente en el desarrollo productivo y, de manera paralela, en el ámbito de la salud y la educación, todo bajo la premisa de un modelo de desarrollo con identidad (Banco Mundial). Tuvo gran incidencia dentro del movimiento territorial, pues consignó la necesidad de contar con una contraparte indígena territorial con la que se acordaría y trabajaría la intervención. Fue este aliciente, junto a otros elementos, uno de los fundantes del movimiento, así como su línea de acción en un primer momento. Los ciclos de intervención se vieron, a su vez, correspondidos por el desarrollo de esta contraparte local. Ambas instancias han vivido, desde entonces, un proceso de creación, consolidación, decaimiento, reinvención y cambio.

A partir del año 2000, el gobierno local se transformó en un actor presente y con incidencia en la comuna aquí analizada, puesto que se produjo la elección de su primer alcalde mapuche, lo que situó en el poder local a un nuevo actor político emergente. Esto significó una serie de cambios a nivel simbólico ${ }^{2}$ dentro de una comuna que hasta entonces había sido encabezada por "gringos"3. Desde entonces hasta el presente, la cabecera municipal ha estado en manos de gobernantes mapuche, lo que implica que todo el proceso organizativo que aquí revisamos se gestó bajo el alero de esos mandatos. Cabe destacar que no necesariamente son relaciones de alianza o de apoyo las que se generaron, como podría esperarse en una relación lineal entre un gobierno a cargo de un indígena y el movimiento indígena. Al contrario, en esta relación hay evidencias del surgimiento de tensiones en torno al hecho de ser un gobierno local "para todos", es decir, para la diversidad poblacional que compone el terri- 
torio y no solo para los indígenas, además de las incidencias de partidos políticos, sistemas clientelares, etcétera.

Es de interés observar como en el año 2000 se pusieron en marcha, de manera paralela, los elementos que influyeron en la formación del movimiento territorial de ese período. De manera previa se conformó el $A D I$, a lo que se sumó el anuncio de inversión por parte del BID a través del Programa Orígenes y luego la elección del primer alcalde mapuche de la comuna. Como apoyo, desde las agencias de cooperación internacional se fue gestando un proceso de formación dirigencial, así como de planificación y ordenamiento territorial que, como veremos más adelante, será uno de los pilares sobre los que se construirán las demandas del movimiento, que aún permanece vigente. La presencia de movimientos etnoterritoriales (Bascopé, 2007), como lo es la identidad lafkenche, y la articulación conformada en ese momento en oposición a la construcción de una carretera que cruzaría las comunidades, fueron otros de los componentes presentes en esta convergencia de situaciones.

La primera administración del gobierno local en manos mapuche (2000-2004) generó una serie de expectativas dentro de la población indígena, pero también cimentó temores en los sectores no indígenas ante la incertidumbre sobre el uso de los recursos municipales y su focalización en los sectores hasta entonces "olvidados" de la gestión edilicia. En la acción municipal comenzó a observarse una tendencia hacia la etnización (Burguete, 2008; Van der Haar, 2007) de la comuna, en un inicio por medio de elementos simbólicos escultóricos y el uso de señalética en mapudungun en los nombres de los servicios, así como la contrata- ción de profesionales mapuche que atendiesen a su gente. Pero el trasfondo será la apropiación de los espacios y los intersticios posibles de construir.

La división administrativa del municipio y los límites que instaurará el ADI no fueron las únicas formas de entender territorialmente este espacio. Sobre estas divisiones administrativas y estatales se reconfigurará también la organización territorial ancestral (Ulloa, 2010), o al menos la concebida como tal. Se recompondrá, de esta manera, el denominado ayllarewe o nueve unidades socioceremoniales, figura organizativa que agrupa por vía parental y ceremonial los linajes y, de esta manera, ordena el tejido sociopolítico del territorio mapuche, así como la congregación ritual del mismo (Faron, 1972). La delimitación del territorio bajo esta mirada no solo tuvo un sentido organizativo, sino también de revitalización cultural, pues permitió poner en valor los espacios ceremoniales vinculados a esta orgánica al retomarse y/o reforzarse las alianzas en el marco de esa ritualidad, que empieza a visibilizarse (Sánchez \& Martínez, 2008).

\section{Movimiento territorial en el Budi}

En agosto del año 2000, a tres años de la creación del primer ADI, se convocó a dirigentes de todas las áreas de desarrollo creadas hasta ese entonces en el país a un encuentro a realizarse en la ciudad de Concepción, instancia en la cual se planteó la necesidad de evaluar lo que hasta entonces había sido la inversión pública en estos territorios. A modo de conclusión de parte de los participantes, se señaló que, aunque se reconocía dicha inversión, los recursos no habían sido adecuadamente focali- 
zados ni se había considerado en su distribución la lógica territorial existente. Se da cuenta así de una política centralizada que no había recogido la participación local en su diseño ni en su implementación. Tres dirigentes del Budi participaron en esta instancia de encuentro y evaluación (Budi, 2002).

Ya de regreso en el territorio y tras lo acordado y analizado en la ciudad de Concepción, surgió la necesidad y el interés de organizar un encuentro al que concurrieran las comunidades pertenecientes al ADI Budi para hacer un ejercicio similar y delinear un marco de incidencia en la ejecución de la intervención estatal que se estaba realizando. Este encuentro fue denominado Kiñe futa trawun taiñ lof mew4. En él las comunidades elaboraron un diagnóstico territorial que abarcó diversos ámbitos, tales como salud, educación, economía y desarrollo cultural. Con base en este trabajo constituyeron sus demandas y propuestas de desarrollo territorial y, con ello, una forma organizativa propia.

Este futa trawun se realizó en diciembre del año 2000 y dentro de la discusión y el debate generado, surgió la necesidad de reconocer la existencia y el rol de las autoridades tradicionales presentes en el territorio para legitimar lo propio como forma organizativa ${ }^{5}$ (Assies \& Gundermann, 2007) y a la vez distintiva en cuanto organización indígena. Se propuso, a modo de orgánica, retomar el liderazgo $\mathrm{y}$, con ello, la validación de los longko y werken o mensajeros, quienes, reinterpretando su antiguo rol, actuarían y se definirían como portavoces desde esta nueva/antigua figura de autoridad. Lo étnico afloró así como sello de este movimiento, ahora indígena. Los werken representantes de cada uno de los sectores en los que se constituyó o reconoció el aylla- rewe fueron escogidos como mensajeros para dialogar y relacionarse con el Estado, lo que revitalizó una forma territorial propia, así como la institución política mapuche correspondiente.

Esta forma de organización no solo incidió de manera interna en el movimiento mapuche en gestación, sino que también fijó los lineamientos sobre los cuales se constituyó la interacción con los agentes estatales que operaban en el ayllarewe. Se produjo una redistribución del poder, en donde la autoridad tradicional -hasta entonces muchas veces relegada a un aspecto simbólico- asumió el liderazgo en los espacios de encuentro con los entes gubernamentales, los cuales pasaron a asumir, en consecuencia, un rol de visita en los territorios. Este cambio, sin duda profundo, cuestionó las formas de interacción local que se habían desarrollado hasta entonces, en las cuales el Estado y sus agentes figuraban como autoridades y las comunidades indígenas como las receptoras de las acciones de estos. Este cambio en la relación tensionó las instancias de diálogo, pero sentó, a la vez, las bases de los procesos participativos y del empoderamiento territorial.

Esta nueva forma organizativa bajo la figura del werken buscó ser un ente de negociación y construcción de políticas públicas participativas. Su eje fue ser un espacio de decisión territorial con incidencia en lo que ocurría en dicho momento en el territorio que vivía un proceso de alta inversión e intervención. Comenzaron a posicionarse los conceptos de inversión pertinente y participativa (Consejo de Werkenes del Budi, 2002), conceptos alimentados con prácticas que buscaban nutrirlos y darles sentido. Cada sector del ayllarewe generó espacios de trabajo y deliberación interna denominados pichitrawun o pequeña reunión. 
Estas instancias aluden a una forma organizativa propia, como lo son los trawun o asambleas, abiertos a todos los participantes, en los que la oralidad constituye el foco de expresión. Dichos espacios serán sintetizados y sistematizados en documentos escritos para permitirles cumplir el rol ya mencionado de negociación. Se propició de esta manera espacios de encuentro y reunión bajo una lógica cultural propia, con miras a construir instrumentos de negociación y diálogo frente al mundo estatal-occidental.

En este proceso de asambleas y discusión se generó el documento "Demandas y propuestas de las Comunidades Mapuche del Territorio Lafkenche, para la elaboración de un Plan Indígena en el Área de Desarrollo Indígena", hoja de ruta del movimiento para enfrentar la negociación con el Estado. Esta no estuvo exenta de tensiones y dificultades: combinó en su accionar espacios de diálogo pero también de enfrentamiento, como fue la ocupación durante una semana del edificio del gobierno local a modo de presión para que el Estado cumpliese con su parte del acuerdo. También significó una demostración de las fuerzas que la organización territorial era capaz de movilizar.

La ocurrencia de esta manifestación de fuerzas implicó, a su vez, una nueva etapa en el movimiento indígena de este territorio. A partir de este hecho, que pudo resultar coyuntural, se decidió, desde la orgánica, buscar una nueva vía de participación política, visualizándose el gobierno local como un ente al cual acceder y desde el cual poder socializar y fijar la agenda del movimiento indígena. Cabe recordar que, como mencionamos anteriormente, durante este período ya se encontraba a la cabeza del municipio un alcalde mapuche. No obstante, este era un líder político que se situaba, en tanto tal, de manera paralela a este proceso organizativo y que, si bien ambos compartían ciertos elementos y demandas, se articulaban en un trabajo conjunto en la medida que esa alianza significara réditos para las dos partes. En el fondo de la relación entre la autoridad local y el movimiento no existía una complementariedad ni una agenda compartida, hecho que se evidenció cuando se produjo la ocupación del edificio municipal, lo cual vino a tensionar la relación hasta entonces de alianza y estrategia común.

La participación política electoral será vista, a partir de ese momento, como un espacio al cual se espera acceder, un espacio de aprendizaje y lecciones que los llevó a adentrarse en la lógica partidista y buscar hacer alianzas con partidos políticos de corte nacional, negociar cupos que les permitiesen insertarse en la competencia política y, con ello, hacerse de un espacio en las agendas políticas tradicionales de los partidos. Junto con este aprendizaje, se apostó al apoyo de las comunidades hacia estos nuevos abanderados políticos del movimiento mapuche. Conseguir el escaño municipal podía ser un logro que redefiniera los rumbos del movimiento, así como la derrota podía convertirse en un espacio de inflexión y de revisión crítica sobre si ese era el paso a seguir en la estrategia de movilización.

A pesar del ímpetu de la organización y de la fuerza alcanzada o al menos demostrada durante sus tiempos de apogeo, la contienda electoral no resultó alentadora para los werken pues no lograron obtener los resultados esperados. Esta derrota sentó las bases para los cuestionamientos acerca del real apoyo de las comunidades al movimiento enarbolado así como si esa era la vía que correspondía 
asumir. Esta situación contribuyó al desarrollo de un período de latencia del movimiento, que dio cuenta de su desgaste y debilitamiento y en el que se reportaron tensiones internas que más tarde incidirían en la caída del mismo. De manera paralela, comenzó también a decaer la intervención estatal y los recursos aparejados. El ya mencionado Programa Orígenes entró en su fase de salida de los territorios. La inversión se terminó y se evidenciaron las consecuencias de una implementación hecha bajo políticas clientelares y asistencialistas (Bello, 2006).

En este período de latencia para el movimiento y de cambio de gobierno local -que se mantuvo en manos de un alcalde mapuche pero perteneciente a un sector contrario- se configuraron nuevas formas de participación comunal y de organización de las comunidades. El referente organizacional que había operado hasta entonces y articulado las demandas indígenas del territorio se comenzó a disolver. Algunos dirigentes continuaron de manera autónoma trabajando en pos de sus lof o de las articulaciones espaciales que representaban, otros se alejaron de estos espacios de trinchera y surgieron nuevos liderazgos y dirigentes, así como nuevas estrategias políticas emanadas desde el gobierno local, que fueron configurando un nuevo espacio de interacción e interrelación entre el territorio y el Estado.

Un primer cambio necesario de destacar en este nuevo ciclo dirigencial tuvo relación con asumir una orgánica alejada del mando tradicional que había sido revalorado y revitalizado previamente. Las autoridades tradicionales serán nuevamente relegadas a su rol simbólico y comenzarán a enarbolarse, por sobre ellas, roles dirigenciales funcionales ${ }^{7}$. Asimismo, el territorio ya no será concebido bajo la figura del ayllarewe tradicional, sino que se redefinirán dichos espacios como sectores numerados o bajo el alero de una asociación indígena ${ }^{8}$. Se dio fin, de esta manera, a la marca simbólica y de impronta cultural acuñada por la actuación de los werken y se adoptó un modelo de trabajo de dirigentes funcionales representantes de un conglomerado de comunidades.

A estos cambios se suma un elemento contextual que también sentó precedentes para una nueva forma de actuar e interactuar con el gobierno local. Nos referimos a la finalización de los programas de alta inversión económica en el territorio ${ }^{9}$. Su incidencia significó un cambio en el interlocutor con el cual se negociaba la organización territorial. Se pasó de ser una orgánica constituida como contraparte del Estado a un momento en que la interlocución se comienza a producir entre el movimiento territorial y el municipio local.

Esta nueva interacción dio paso al surgimiento de nuevos actores. Se forjó así la figura del "gestor territorial", similar a un bróker (Auyero, 2002; Bascopé, 2007), cargo que recayó en funcionarios municipales con grados de confianza con el edil y con conocimiento del territorio y de los actores que en él se desenvuelven. La relación alcalde-dirigentes indígenas era facilitada y coordinada por este mediador, atribuyéndosele el poder de dirimir temas y demandas de los territorios, resoluciones que lograba dada su cercanía con el alcalde de turno.

Bajo esta modalidad de organización e interlocución, que implicó que cada uno de los sectores en los que se "dividió" simbólicamente el territorio trabajase de manera autónoma con su gestor territorial designado, se produce una desarticu- 
lación de la mirada global en cuanto cada sector comienza a velar por sus propios intereses y la consecución de sus demandas. Esto fomentó un enfoque espacial micro (sectores) por sobre la noción de territorio mapuche, ADI o, inclusive, comuna, como operaba anteriormente. Se generó, bajo esta lógica, una competencia entre sectores y asociaciones por conseguir sus demandas y se rompió la articulación territorial y la mirada holística del espacio (Ospina, 2006).

Debido a la necesidad de mantener algún tipo de impronta identitaria indígena en esta nueva organización, se optó por la designación de una autoridad tradicional que oficiase la coordinación de las instancias de trabajo que se generaban. Bajo esta autoridad tradicional se erigió la figura de un secretario ejecutivo, encargado de coordinar una mesa de trabajo que articulase a estos sectores y sus representantes. Como mencionamos anteriormente, el municipio era el interlocutor con quien dialogar y para ello se designó a dos werken para oficiar dicho diálogo, quienes debían actuar como representantes de la mesa territorial conformada, mas no de los territorios o de los longko, como sucedía bajo la figura organizativa anterior.

Otro elemento interesante de este nuevo momento organizacional está relacionado con la inclusión de sectores de la comuna de Saavedra que anteriormente habían sido relegados del movimiento indígena, ya fuese por su carácter de no indígenas o por no pertenecer a la territorialidad definida como ancestral. Bajo esta nueva propuesta se incorporaron a la mesa territorial sectores urbanos nominados usualmente como no indígenas, por ser espacios habitados mayormente por población colona y con demandas, dado su carácter urbano, diferentes a las de los sectores rurales.
Asimismo, se integró un sector hasta entonces excluido de las delimitaciones tradicionales, pero que apelaba a la identidad indígena, el sector norte de la comuna, compuesto por comunidades mapuche y colonas empobrecidas. Esta población indígena, que si bien forma parte del territorio comunal, es vista como un sector con mayor pérdida de sus tradiciones culturales e identidad por encontrarse en contacto directo con habitantes colonos, además de estar expuesta a una mayor conectividad y vinculación con centros urbanos más grandes.

Durante este período alcaldicio y hasta la fecha que abarca la etnografía de este trabajo (2012), se sucedieron dos gobiernos locales encabezados por personas mapuche, en los que se privilegió y potenció esta última forma organizativa, la cual dota de mayor protagonismo a las instancias municipales y las organizaciones funcionales del territorio. La cabecera de la mesa de trabajo recae implícitamente en el municipio, lo que impide, o más bien dificulta, la aparición de liderazgos que se opongan o se muestren ajenos a esta instancia local. Por lo mismo, promueve las redes clientelares y los pequeños cacicazgos apoyados por este poder local, quienes son finalmente los que terminan organizando las demandas territoriales y las interlocuciones con el Estado.

\section{Partidos políticos, gobiernos locales y movimiento territorial}

Los partidos políticos de presencia nacional y representativos de macrosectores políticos como los sectores liberales económicos vinculados a la centro-derecha y aquellos denominados, desde el retorno a la democracia, como Concertación de Partidos por la Democracia ${ }^{10}$, 
vinculados a la centro-izquierda- se constituyen en un actor relevante al interior de los territorios indígenas. Sus intereses influyen en la puesta en marcha de una serie de acciones tendientes al fraccionamiento y la coaptación de la población en pos de la consecución de adeptos para sus filas partidarias. Esto conlleva la irrupción de sus programas políticos, así como de sus candidatos y figuras a potenciar. Al ser partidos políticos de presencia nacional, no necesariamente cuentan con una agenda política favorable a los pueblos indígenas o una representación interna de estos en la orgánica partidaria. Si bien se intentó crear un partido político mapuche en el territorio de la Araucanía, por diversas razones, que no caben en este artículo, dicha instancia no pudo concretarse.

La figura de los partidos políticos será, entonces, una figura asociada al poder y a recursos económicos y, como tal, una fuente de validación para líderes y dirigentes de la zona que intentan llegar a instancias del gobierno local, principalmente. Bajo este marco, la adscripción a los partidos político posee un fin instrumental (Bascopé, 2007) por parte de quienes buscan su apadrinamiento. Estas condiciones los obligan a adecuarse a sus reglas del juego el tiempo que dure la adscripción, la cual suele estar vinculada a los períodos electorales. Esta estrategia es asumida también por los conglomerados que por medio de la "entrega de cupos a dirigentes locales" buscan posicionarse en otros territorios y con ello aumentar su presencia numérica en cargos a nivel nacional.

La participación partidista es un elemento estratégico de consecución de poder por parte de los dirigentes y a la vez de los partidos políticos. Implica un juego que pone en relación la existencia de redes personales y comunita- rias de capital social para la captura hacia estos potenciales líderes y su "militancia". También puede ser un instrumento para la búsqueda de votos. Este juego deja en evidencia una alta movilidad de los dirigentes/candidatos entre los partidos, con los que establecen alianzas de acuerdo con los intereses del momento coyuntural eleccionario. No es extraño observar cómo estos dirigentes se presentan en una elección bajo un conglomerado político y, de no conseguir el triunfo, aparecen en la elección siguiente asociados al bloque contrario. El fin último es la consecución del espacio de poder.

Esta movilidad y competencia política incidirá en las relaciones internas del territorio y sus organizaciones. Los pactos confrontarán y tensionarán a dirigentes, se generarán quiebres tanto a nivel organizacional como comunitario $y$, con ello, también se resentirán los lazos de parentesco y las diversas alianzas que se viven en el territorio. Tal como señala Calla, la cultura partidista se vuelve desestructurante, así como un elemento aculturizador dentro de los territorios indígenas (1999). La lógica competitiva alterará la cotidianeidad de estos espacios cada vez que se sucedan los procesos eleccionarios locales pues se termina apostando a la opción que permita obtener más réditos.

Encontramos esta lógica política tras todos los movimientos y las organizaciones territoriales aquí analizadas. En el caso del Consejo de Werkenes, este recurrió al entonces pacto de izquierda denominado Juntos Podemos, conformado por el Partido Comunista y el Partido Humanista. Esta alianza se estableció desde una postura funcional, puesto que cada uno de los werken y los dirigentes tenían sus propias simpatías partidarias. Primó la necesidad del objetivo propuesto, que era el posicionamiento 
político del movimiento por medio de la participación en el gobierno local. Finalmente, como ya lo vimos, no lograron su objetivo y la alianza política forjada se se disolvió tras las elecciones.

La mesa territorial no ha fijado dentro de sus líneas de acción la participación política propia, es decir, con un representante surgido de su orgánica, por lo que no se han visto expuestos a esta decisión de involucramiento y alianza. No obstante, su surgimiento al alero de los alcaldes de turno los obliga a asumir la alianza política del conglomerado que apoye al edil que ha estado en funciones ${ }^{11}$.

Es interesante ver que, si bien los partidos políticos operan buscando conseguir adeptos, al menos permiten a los territorios cierta independencia pues la negociación que se produce es por los cupos, no por los nombres de quienes los ocuparán. Los partidos buscan mantener las cabezas alcaldicias o los asientos concejales, pero no necesariamente posicionar a sus líderes, muchas veces ajenos a los territorios. Más bien se apuesta por quienes posean las mayores posibilidades de elección, de manera de asegurar numéricamente su presencia a nivel nacional, así como también la irrupción de su agenda y conseguir apoyos locales para escalas políticas mayores, como las elecciones parlamentarias.

\section{Demandas sociales emergentes desde los territorios}

Las dos formas de organización territorial que aquí hemos analizado crearon documentos de trabajo como la Mesa de diálogo y planificación del desarrollo para un reencuentro histórico (Comuna de Saavedra. Plan de Desarrollo
Comunal 2011 - 2014), en los que plasmaron su mirada sobre el territorio y sus reivindicaciones, de ahí que resulten una guía para la revisión de sus demandas y su existencia como movimientos. Analizar estos documentos hará destacar las diferencias y las semejanzas en cómo se concibe y desea desarrollar el devenir de un territorio y el trasfondo que esconde la idea de constituirse como un movimiento territorial.

Los campos de acción en los que se desglosan las demandas son similares en ambas aproximaciones y, por tanto, en los dos momentos organizativos y dirigenciales. El sector productivo es el de mayor sensibilidad y en el que se cifran las esperanzas y demandas más importantes, dado los altos índices de vulnerabilidad socioeconómica que suelen presentar los territorios indígenas en Chile.

En el caso del Consejo de Werkenes, su mirada estaba puesta en la forma de insertarse en los mercados agrícolas de manera directa y sin intermediarios, como ocurre hasta hoy en día. Desde la óptica de la dirigencia, esto implicaba contar con sistemas de mejoramiento de tierras, adquisición de maquinarias, entre otro tipo de necesidades. El fin estaba en la inserción económica territorial que permitiese la autonomía y autogestión económica del territorio por sobre la dependencia de intermediarios. La mesa territorial, por su parte, centraba el acento en la necesidad de tierras y de un apoyo técnico que permitiese mejorar la productividad de estas. El foco estaba puesto en la producción agrícola por sobre la comercialización y la gestión económica del territorio. Ambas miradas, si bien se centran en el debate productivo, dan cuenta de acercamientos divergentes a la manera de concebir el desarrollo económico y, más aún, las posibilidades de 
autonomía territorial factibles de conseguir bajo estas perspectivas.

El campo educativo es otro eje de las demandas de los movimientos territoriales. Aquí el énfasis estaba puesto en la necesidad de contar con una educación culturalmente pertinente para los territorios. Junto a esa mirada cultural, se planteaba también la necesidad de propiciar la continuidad de los estudios en la localidad y, por lo tanto, la creación en ella de liceos técnicos profesionales que formasen a los jóvenes mapuche sin que estos tuviesen que vivir la migración estacional que supone salir a estudiar a otras comunas o centros urbanos. Se buscaba, de esta manera, la mantención de la población en sus espacios territoriales, con componentes de fortalecimiento cultural que contribuyeran a la mantención, la revitalización y la perdurabilidad de su cultura.

Un tercer elemento que será parte de este análisis es el campo denominado territorio, presente en ambos documentos. La importancia de la presencia de este apartado recae, precisamente, en la exposición de la conceptualización y el entendimiento que se tiene de este y, con ello, de la manera cómo se enarbolan las demandas que definen su posicionamiento como un movimiento que se constituye desde el territorio.

En el primer documento, perteneciente a la orgánica de los werken, se buscó posicionar la reivindicación cultural y la reconstrucción del territorio tradicional mapuche. En él se aglutinaron demandas y miradas vinculadas a la necesidad de asegurar los derechos colectivos de los pueblos, en especial el derecho a la tierra, entendiendo por ello la necesidad de la restitución territorial por parte del Estado como parte del saldo de la deuda histórica que se contrajo tras la ocupación militar del terri- torio. Se apeló a este como una necesidad de recuperar lo propio, lo perdido tanto material como culturalmente.

En los postulados del segundo momento organizativo, regido bajo la lógica de una mesa que articula asociaciones indígenas de énfasis productivo, esta mirada sobre el territorio cambia por una que apela a la necesidad de contar con mayores superficies de tierra que puedan ser destinadas a los procesos productivos para mejorar los índices económicos de vulnerabilidad. En esta percepción, la tierra es vista bajo una lógica material, lo que diluye la perspectiva anterior de corte más político y reivindicativo de los derechos. Ambas miradas son un reflejo de los procesos que constituyen a cada uno de los movimientos analizados.

\section{Conclusiones}

Las políticas surgidas en la década de 1990 que intentaron saldar la deuda histórica existente hacia los pueblos indígenas generaron una oleada de intervenciones e inversiones que alteraron la realidad de estos espacios y, con especial énfasis, la relación entre gobiernos locales, dirigentes y sus bases. Tal como lo planteó Ospina (2006) para el caso ecuatoriano -que puede ser extrapolado a gran parte de la realidad latinoamericana-, en este juego de incidencias externas y recibimiento de recursos, las organizaciones se ven altamente tensionadas y muchas veces destrozadas a causa de la división que se genera en su interior y la competencia que surge entre ellas para la consecución de los anunciados proyectos que se ofrecen a los territorios. Las políticas gubernamentales promueven, sobre todo, las miradas individuales sobre el 
desarrollo y la mejora de la calidad de vida, tendencia que actúa en detrimento de los alcances comunitarios o de los movimientos.

El panorama o contexto social que se ha vivido durante los años aquí analizados (2000-2012) no presenta grandes variaciones en lo que a cifras de estadísticas sociales se refiere. La tasa de pobreza comunal se sigue situando, en cada nueva medición, entre los cinco primeros lugares a nivel nacional. Esto da cuenta de que con este tipo de modelo político los territorios han visto más bien mermadas sus condiciones de vida, tal como lo reflejan las mediciones estadísticas ${ }^{12}$. La permanencia de este contexto nos sitúa ante una continuidad de las condiciones detonantes de la movilización. La forma distinta de hacerlo es la que caracteriza a cada uno de los actores mencionados. Los recursos presentes en el territorio también son decidores en este actuar.

La constitución de un movimiento indígena está dado por un juego de construcción de identidades negociadas que dan cuenta de la puesta en escena de identidades performáticas (Assies, 1999), construidas sobre la base del contexto de negociación con el Estado y los otros organismos intervinientes en el espacio. Tal como lo plantean Assies, Van der Haar \& Hoekema, esta reorganización étnica es producto de la "interacción entre la alteridad negociada y la continuidad cultural" (1999, p. 515). Su resultado determina la puesta en escena de prácticas y elementos culturales que reafirman la necesidad de resistencia y continuidad de los pueblos indígenas.

El Consejo de Werkenes, si bien planteó una discusión y una reivindicación asentadas en la necesidad de un reconocimiento identitario y territorial, no podía obviar que uno de los ejes que lo movilizaba era la necesidad de paliar la pobreza que se vive en sus territorios, lo que lo condujo a la necesidad de plantear demandas de reparación de caminos, aumento de subsidios, etc. (Sociedad de Profesores Mapuche Kimeltuchefe, 2003). No se puede construir una mirada de desarrollo territorial si no se han suplido las necesidades básicas de su población.

La asociatividad expresada en la conformación del Consejo de Werkenes buscó sentar las bases de una nueva forma de relación e interlocución con el Estado, siendo el punto fundante de esta relación el cambio en la verticalidad existente hasta hoy en día. En esta se asume una actitud pasiva ante el Estado, la institucionalidad y todo proyecto o programa que se implante para la mejora de las condiciones de vida.

Esta nueva orgánica buscaba un empoderamiento de los participantes a través de un cambio en las formas de actuar y relacionarse. Se configuraron como una contraparte activa, con poder de decisión y resolución respecto de los temas de su interés. Se volvieron un actor protagonista de su devenir, pues junto con fijar las formas de interrelación y control del diálogo, incluyeron en su proceder elementos culturales que revitalizaban las formas de organización tradicional. Esto hizo posible rearticularlas en el nuevo marco de acción.

En el período estudiado estos movimientos establecieron relaciones de corte semiclientelar con sectores o personeros políticos a cambio de ganancias electorales para los segundos y por medio de las cuales se establecieron alianzas y relaciones de reciprocidad que les permitieran incidir en las intervenciones a realizar en el territorio. El acuerdo siempre se estableció con miras a un futuro electoral, donde se podían obtener los réditos de la relación. 
Si bien a lo largo de este proceso organizacional notamos la existencia de cambios en los procesos vividos dentro del territorio, de manera paralela vimos que se produjo también una continuidad, una permanencia, de ciertos dirigentes. Han prevalecido, efectivamente, los líderes que se superponen o son autónomos al tipo de demanda u organización existente, que son dirigentes innatos y reconocidos como tales y que formaron parte de los diversos procesos vividos. Se creó, de esta manera, una trayectoria dirigencial que avala a la persona en su liderazgo. Sin embargo, la mantención de la dirigencia, si bien dota de continuidad al proceso, llega un momento en que también lo encierra en sí mismo y, con ello, acota el campo de discusión y las demandas a generar.

En el ámbito de las demandas de los movimientos, se observó una tendencia a la reivindicación de necesidades con soluciones a corto plazo, en detrimento de un énfasis en procesos de mayor alcance. La interrelación entre las orgánicas y los gobiernos locales podría ser uno de los factores incidentes en esta visión más inmediata en cuanto a las soluciones a las necesidades y las demandas, pues estas quedan constreñidas a los períodos alcaldicios y las alianzas ahí forjadas.

La necesidad de apoyo municipal en la gestión de las organizaciones también debe tomarse en cuenta, pues de este depende el financiamiento de los requerimientos logísticos que facilitan la labor de los líderes territoriales. Durante este trabajo se pudo constatar la existencia de un estrecho vínculo entre la administración municipal y la organización territorial, no desprovisto de tensiones, pero en el que se busca por lo general un consenso para actuar de manera unitaria, más que como entes opuestos. Esta relación, permeada por el clientelismo y la política subsidiaria, incidió en el establecimiento de los límites y los campos de acción de la organización. Quienes no deseaban participar en ese tipo de espacio terminaron marginándose la mayoría de las veces. Tampoco se registró, durante el tiempo de estudio, el surgimiento de un movimiento que buscara romper con esta alianza o que intentara contraponerse a esa lógica de actuación.

El alcance e ímpetu logrado por el Consejo de Werkenes durante su tiempo de apogeo, en conjunto con la asunción del primer alcalde mapuche en la comuna, incidieron con fuerza en la subjetividad de la población mapuche comunal, la cual, al sentirse parte de la toma de decisiones locales, aumentó su participación política activa. La mayor visibilidad de los mapuche en el espacio urbano fue fuente de cambio y de tensiones por la reticencia que despertó en los espacios conservadores que se creyeron amenazados por esta irrupción mapuche en el gobierno local. El temor a la "mapuchización" de la comuna se mantuvo latente los primeros años de este cambio. El alcalde que encabezó este proceso debió dar muestras de una amplia representatividad y de cuidar los intereses de todos los habitantes de la comuna al mismo tiempo que debía reforzar los elementos constituyentes de su adscripción étnica. Se movió, así, en un precario equilibrio de convivencia intercultural.

En el plano de la participación política, la forma de actuar se rigió por las reglas del juego que la institucionalidad impone, al mismo tiempo que se crean estrategias que permiten sacar el mayor provecho de los ámbitos de negociación. Los sistemas de elección comunal conforman un espacio de interés y de esferas de acción 
variadas en las que se despliegan un sinnúmero de formas de participación y de dinámicas propias del mundo de los partidos políticos, las alianzas y los votos.

\section{Los movimientos y las organizaciones aquí} analizados son descritos desde una mirada local a un sistema macro de articulación de organizaciones sociales, políticas estatales y estructuras políticas, en la que lo local, no obstante, provee a estas relaciones de un sentido particular marcado por el espacio en que se desenvuelven. Así, las dinámicas macro se cargan de la identidad y las realidades locales.

\section{Notas}

${ }^{1}$ La denominación "mapuche lafkenche" responde a la identidad territorial de las poblaciones mapuche vinculadas al espacio costero, en este caso en una comuna aledaña al océano Pacífico, que cuenta además con un gran lago, en cuyas riveras se sitúan las comunidades mapuche.

${ }^{2}$ Para ver más sobre este proceso revisar Caniguan, N. (2005).

${ }^{3}$ El término "gringo" suele ser utilizado para describir a personas no mapuche, generalmente de tez blanca y cabellos claros; no necesariamente corresponde a gente venida de otros países.

${ }^{4}$ Cuya traducción podría ser "gran reunión en nuestra tierra común".

${ }^{5}$ Cabe consignar, que tras la promulgación de la Ley 19.253 o Ley Indígena, se crea la figura jurídica de comunidades y asociaciones indígenas, las que configuran una nueva forma organizativa en los territorios indígenas bajo la modalidad funcional de presidente, secretario y tesorero, figuras regidas por reglamentos que estipulan sus funciones y tiempos de representación en el cargo, y que se superponen a formas organizativas propias o culturales.

${ }^{6}$ Autoridad política tradicional mapuche encargada de la organización del lof o comunidad. La traducción del término longko significa cabeza.

${ }^{7}$ Entiéndase por estos presidentes de comunidades y/o asociaciones indígenas electos en función de la ley 19.253

${ }^{8}$ Las asociaciones indígenas son figuras establecidas por la Ley 19.253 o Ley Indígena, la cual señala en su artículo 36 que esta corresponden a "la agrupación voluntaria y funcional integrada por, a lo menos 25 indígenas que se constituyen en función de algún

interés y objetivo común [...] las asociaciones indígenas no podrán atribuirse la representación de las comunidades indígenas".

${ }^{9}$ Nos referimos especialmente al Programa Orígenes, el que si bien continuará operando en una segunda fase, en esta ocasión disminuirá sus niveles de inversión y, con ello, de expectativas. También se focalizará en trabajar en territorios que hasta ahora no habían sido incluidos.

${ }^{10}$ Hoy denominado Nueva Mayoría por la inclusión del Partido Comunista, que había estado fuera del pacto anteriormente mencionado. En el momento en que se escribe este artículo se encuentra en un proceso de ajustes internos tras la aparición de otro conglomerado de izquierda que ha cuestionado sus bases denominado Frente Amplio.

${ }^{11} \mathrm{Si}$ bien se han sucedido dos alcaldes desde el momento en que asumió esta forma organizacional, cabe reseñar que ambos cuentan con trayectorias políticas que les ha significado participar de estas alianzas electorales diversas. Ambos alcaldes tuvieron diversos momentos de participación en elecciones que los llevó a establecer relaciones con partidos políticos que les facilitasen cupos, así como con procesos coyunturales del territorio, compromisos que implicaron el traspaso de votantes o apoyos internos.

${ }^{12}$ En las últimas mediciones ha aparecido la comuna de Ercilla como uno de los territorios con mayor tasa de pobreza, situación asociada a la expansión forestal de la zona y, a causa de esta, a la alta erosión de los suelos, la escasez de agua y otras situaciones que han afectado la calidad de vida de sus habitantes. 


\section{Referencias bibliográficas}

Assies, W. (1999). Pueblos indígenas y reforma del Estado en América Latina. En Assies, W., Van der Haar, G. \& Hoekema, A., El reto de la diversidad (pp. 21-56). México: Colegio de Michoacán.

Assies, W. \& Gundermann, H. (2007). Movimientos indígenas y gobiernos locales en América Latina. San Pedro de Atacama: IIAM-Universidad Católica del Norte.

Assies, W., Van der Haar, G., \& Hoekema, A. (1999). El reto de la diversidad. México: Colegio de Michoacán.

Auyero, J. (2002). Clientelismo político en Argentina: doble vida y negación colectiva. Perfiles Latinoamericanos, (20), 33-52.

Barth, F. (1976). Los grupos étnicos y sus fronteras. La organización social de las diferencias culturales. México: Fondo de Cultura Económica.

Bascopé, J. (2007). Entre el liderazgo y la representación: Alcances y límites del gobierno local indígena en Tirúa. En Assies, W. \& Gundermann, H., Movimientos indígenas y gobiernos locales en América Latina (pp. 258-289). San Pedro de Atacama: IIAMUniversidad Católica del Norte.

Bello, Á. (2006). Programa Orígenes y política pública del gobierno de Lagos hacia los pueblos indígenas. En Yañez, N. \&. Aylwin, J., Gobierno de Lagos, los pueblos indígenas y el "nuevo trato". Las paradojas de la democracia chilena (pp. 117-135). Santiago: Lom.

Bengoa, J. (2000). La emergencia indígena en América Latina. México: Fondo de Cultura Económica.

Burguete, A. (2008). Gobernar en la diversidad en tiempos de multiculturalismo en América Latina. En Leyva, X., Burguete, A. \& Speed, Sh., Gobernar (en) la diversidad: experiencias indígenas desde América Latina. Hacia la investigación de co-labor (pp. 1564). México: CIESAS.

Calla, R. (1999). Indígenas, ley de participación popular y cambios de gobierno en Bolivia (1994-1998). En Assies W., Van der Haar, G. \& Hoekema, A., El reto de la diversidad (pp. 149-180). México: Colegio de Michoacán.

Caniguan, N. (2005). Municipio mapuche. Estudio de caso en la comuna de Saavedra. (Tesis inédita de licenciatura en antropología social). Universidad Academia de Humanismo Cristiano, Santiago.
(2015). Trayectorias políticas. Historias de vida de alcaldes mapuche. Santiago: RIL.

Consejo de Werkenes del Budi (2002). Demandas y propuestas de las comunidades del territorio lafkenche, para la elaboración de un Plan Indígena en el Área de Desarrollo Indígena del Budi. Puerto Saavedra. Documento de trabajo.

Espinoza, C. (2017). Procesos etnopolíticos en la transición democrática chilena. Gobiernos locales y la vía política mapuche. Cuadernos de Antropología Social, (45), 21-36.

Faron, L. (1972). Estructura social mapuche. México: Instituto Indigenista Americano.

Guber, R. (2001). La etnografía. Método, campo y reflexividad. Buenos Aires: Norma.

INE (2017). Censo de Población y Vivienda 2017. Santiago: Instituto Nacional de Estadísticas.

Ospina, P. (2006). En las fisuras del poder. Movimiento indígena, cambio social y gobiernos locales. Quito: Instituto de Estudios Ecuatorianos.

Pairican, F. (2014). Malón. La rebelión del movimiento mapuche. Santiago: Pehuén.

Sánchez, C. \& Martínez, A. (2008). Pueblos originarios en la metrópoli de la Ciudad de México: gobernar en la macrocomunidad de Milpa Alta. En Leyva, X., Burguete, A. \& Speed, Sh., Gobernar (en) la diversidad: experiencias indígenas desde América Latina. Hacia la investigación de co-labor (pp. 229-270). México: CIESAS.

Sociedad de Profesores Mapuche Kimeltuchefe (2003). Werken wall lof Budi. Recuperado de https://www.youtube.com/ watch?v=QqSwyNdzjAc

Ulloa, A. (2010). Reconfiguraciones conceptuales, políticas y territoriales en las demandas de autonomía de los pueblos indígenas en Colombia. Tabula Rasa, (13), 73-92.

Van der Haar, G. (2007). Levantamiento zapatista, indígenas y municipio en Chiapas, México. En Assies, W. \& Gundermann, H., Movimientos indígenas y gobiernos locales en América Latina (pp. 199-225). San Pedro de Atacama: IIAM-Universidad Católica del Norte. 